\title{
The Use of Platelet Rich Plasma in Chronic Plantar Fasciitis
}

\author{
MOHAMED A.I. ABUALSOUD, M.Sc.; MAMDOUH F. LASЮN, M.D.; \\ AHMED EL-SAYED EL-TANTAWY, M.D. and MOHAMED OSAMA RAMADAN, M.D.
}

The Department of Orthopedic Surgery, Faculty of Medicine, Tanta University

\begin{abstract}
Background: Chronic plantar fasciitis is the most common cause of foot complaints making up to $11-15 \%$ of the foot symptoms requiring professional care among adults. Also, it is a common problem that affects sport participants as well as inactive middle-aged individuals. Many modalities of treatment were prescribed to relieve the symptoms such as rest, Nonsteroidal Anti-Inflammatory Drugs (NSAIDs), bracing, physical therapy and corticosteroid injection. Newer treatment modalities have been tried, such as extracorporeal shock wave treatment, iontophoresis, and injection of botulism toxin. In case of lack of response to conservative treatment, the last resort is surgery with the primary objective of relieving pain. One novel treatment strategy is the use of local injection of platelet rich plasma. These platelets release a large proportion of biologically active growth factors that are thought to accelerate and improve the regeneration and healing process.
\end{abstract}

Aim of Study: This study is designed to be a prospective study, aiming to evaluate the clinical outcome of patients who were diagnosed to have chronic plantar fasciitis and treated with platelet rich plasma local injection.

Patients and Methods: The study was conducted on 40 patients (16 males-24 females) from September 2017 to August 2018 with chronic planter fasciitis attending the outpatient clinic of the Orthopedic Department of Tanta University Hospitals. Their ages ranged from 30 to 57 years with mean age of 42.17. All patients had inferior heel pain that is usually worse with their first steps in the morning or after a period of inactivity, with maximal tenderness over the antero-medial aspect of the inferior heel and not responding to conservative treatment. Patients were treated by local injection of platelet rich plasma at maximal tender point of the heel. They were followed-up after one month, two months, three months and six months using Visual Analogue Scale, Roles and Maudsley Score, and American Orthopedic Foot and Ankle Society Score.

Results: All patients were successfully followed-up for 6 month. According to VAS of pain, the mean VAS of pain had improved from $8.03 \pm 1.12$ pre-injection to $2.28,1.18$ post injection. According to Roles and Maudsley score, 9 patients with excellent results, 22 patients with good results, 7 patients with accepted results and 2 patients with poor results. According to AOFAS, the mean of AOFAS had improved from $49.80_{-3}$ 8.93 pre-injection to $82.0-8.94$ post injection. The final end

Correspondence to: Dr. Mohamed A.I. Abualsoud, The Department of Orthopedic Surgery, Faculty of Medicine, Tanta University results were satisfactory in 31 patients out of 40 and 9 patients ended by unsatisfactory results. There were no complications reported during follow-up of the cases.

Key Words: Platelet rich plasma-Chronic plantarfasciitis.

\section{Introduction}

CHRONIC plantar fasciitis is the most common cause of foot complaints and, making up 11-15\% of the foot symptoms requiring professional care among adults [1].

It is a common problem that affects sport participants as well as inactive middle-aged individuals [2]. Approximately $50 \%$ of patients with heel pain will have heel spurs. It is now widely accepted that heel spurs can occur with Plantar Fasciitis $(\mathrm{PF})$, but they are not essentially the cause $[3,4]$ The diagnosis is based on the typical history and the finding of localized tenderness in the medial calcaneal tubercle $[\boldsymbol{s}$.

It is a disorder that results in pain in the heel and bottom of the foot [6]. The pain is usually most severe with the first steps of the day or following a period of rest [7]. Pain is also frequently brought on by bending the foot and toes up towards the shin and may be worsened by a tight Achilles tendon $[7,8]$. The condition typically comes on slowly [8]. In about a third of people both legs are affected [6]

Conservative treatment of plantar fasciitis has many ways including physiotherapy, plantar-fasciastretching exercises, icepacks, night splints, prefabricated and custom-made insert, shoe modification and Non-Steroidal Anti-Inflammatory Drugs (NSAIDs) [2] .

Local injection modalities are commonly used secondary to conservative therapies in the treatment of patients who have resistant plantar fasciitis as corticosteroid and platelet-rich plasma. PlateletRich Plasma (PRP), which is a natural concentrate 
of autologous growth factors, is now being widely used in different fields of medicine for its ability in aiding the regeneration of tissue that has a low healing potential. Local injection of PRP is a new technique, which has recently been used for the treatment of plantar fasciitis [5]

Recently, promising results were reported with the use of Platelet-Rich Plasma (PRP) injections for treating muscle and tendon injuries and degeneration. PRP contains several different growth factors and other cytokines that can stimulate healing of soft tissue and joints. (PRP) is promoted as an ideal autologous biological blood derived product, which can be exogenously applied to various tissues where it releases high concentrations of platelet derived growth factors that enhance wound, bone, also tendon healing [1]

The purpose for using PRP in orthopedics is to increase tendon regenerative abilities with a high content of cytokines and cells, in hyper physiologic doses, which should promote cellular chemo-taxis, matrix synthesis, and proliferation [2].

In Europe and the United States, there is an increasing prevalence of the use of autologous blood products to facilitate healing in a variety of applications. New data exist about specific growth factors, which play an important role in the healing process. With that knowledge, there is interest in application of concentrated platelets, which release a supra-maximal quantity of these growth factors to stimulate recovery in non-healing injuries [2] .

For 20 years, the application of autologous PRP has been safely used and documented in many fields including; orthopedics, sports medicine, dentistry, ENT, neurosurgery, ophthalmology, urology, wound healing, etc. [9] .

Platelet-Rich Plasma (PRP) as a clinical treatment for bone, muscle, tendon, and cartilage injury has gained popularity in the field of orthopedic sports medicine [10].

Platelets are small, non-nucleated bodies in peripheral blood that are known primarily for their role in hemostasis. Platelets contain a number of proteins, cytokines, and other bioactive factors that initiate and regulate basic aspects of wound healing. A number of growth factors released by platelets during degranulation including plateletderived growth factor, transforming growth factor $\beta$, type I insulin-like growth factor (IGF-1), vascular endothelial growth factor, and hepatocyte growth factor have been implicated to have beneficial effects in tissue repair and proliferation [9].
Normal platelet counts in blood range from $150000 / \mathrm{mcL}$ to $350000 / \mathrm{mcL}$. Plasma is the fluid portion of blood and contains clotting factors and other proteins and ions. Platelet-rich plasma, with a platelet concentration of at least 1000000 platelets $/ \mathrm{mcL}$ in $5 \mathrm{~mL}$ of plasma is associated with the enhancement of healing. Platelet-rich plasma contains a 3 to 5 fold increase in growth factor concentrations [11].

\section{Patients and Methods}

The study was conducted on 40 patients from September 2017 to August 2018 including patients with chronic plantar fasciitis not responding to conservative treatment presenting to the outpatient clinic of the Orthopedic Department of Tanta University Hospitals. Patients were treated by local injection of platelets rich plasma and completed at least 6 months of follow-up.

\section{1- Inclusion criteria:}

The followings were prerequisites of the inclusion criteria of this study:

- Having inferior heel pain that is usually worse with their first steps in the morning or after a period of inactivity, with maximal tenderness over the anteromedial aspect of the inferior heel.

- Patients not responding to conservative measures as ice, rest, stretching, anti-inflammatory medication and physical therapy for more than 3 months.

- Patients with Visual Analogue Scale of pain (VAS) more than 5 in the morning.

\section{2- Exclusion criteria:}

The followings were excluded from this study:

- Recent use of corticosteroids during last 2 month.

- Recent trauma to heel.

- Immunocompromised patients due to liability for infection.

- Vascular insufficiency (impalpable pedal pulse).

- Recent febrile or infectious disease.

- Peripheral neuropathy related to heel pain.

- Bad soft tissue envelope around the heel.

- Pregnancy.

- Local infection at the site of the procedure.

- Earlier surgery including endoscopic plantar fascial release or open plantar fascial release.

- History of any malignancy (including hematologic $\&$ non hematologic malignancies).

- History of severe anemia, thrombocytopenia (platelets $<100 \mathrm{mcL}$ ) or bleeding tendency. 


\section{Injection procedure:}

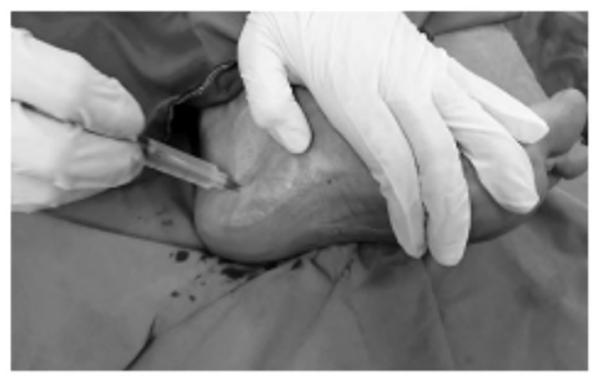

(A)

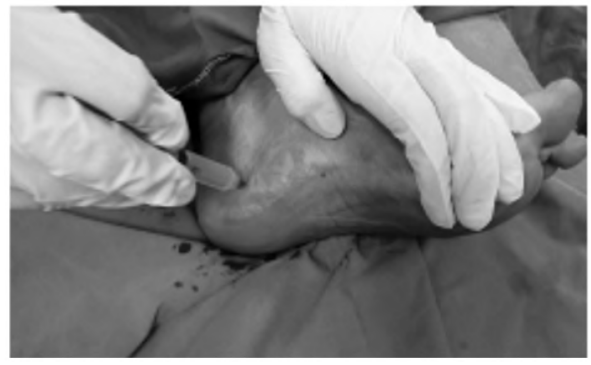

(C)

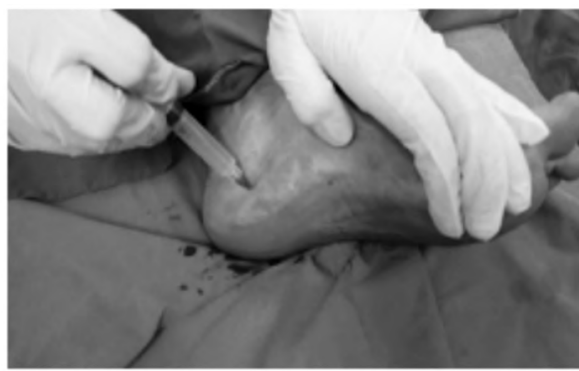

(B)

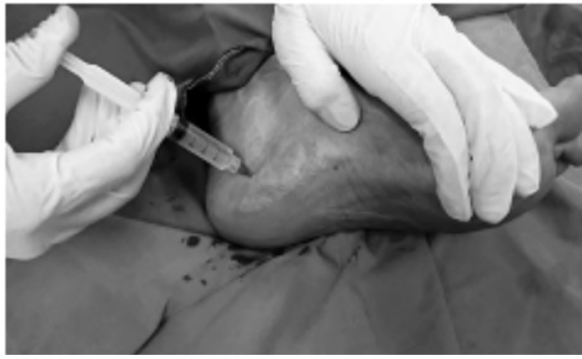

(D)

Fig. (1): PRP injection using a peppering technique.

Three $\mathrm{ml}$ of liquid PRP after addition of $0.5 \mathrm{ml}$ of calcium chloride were injected in a sterile condition using a $22 \mathrm{G}$ needle at maximal tender point at the heel by medial approach using a peppering technique. This technique involved a single skin portal followed by 9 multiple penetrations of the fascia while injecting equal amounts of platelet rich plasma. Patients were observed in supine position for 15-20min afterwards to look for any adverse reaction to injection, and then discharged home.

\section{Statistical analysis:}

Data were fed to the computer and analyzed using IBM SPSS software package Version 20.0. (Armonk, NY: IBM Corp). Qualitative data were described using number and percent. The Kolmogorov-Smirnov test was used to verify the normality of distribution quantitative data were described using range (minimum and maximum), mean, standard deviation and median. Significance of the obtained results was judged at the $5 \%$ level.

\section{Results}

Satisfactory results were found in 31 patients $(77.5 \%)(9$ patients $(22.5 \%)$ with excellent results and 22 patients (55\%) with good results). The unsatisfactory results were found in 9 patients $(22.5 \%)$ (7 patients (17.5\%) with accepted result and 2 patients (5\%) with poor result) as shown in (Table 1).
Table (1): Distribution of the studied cases according to final end result.

\begin{tabular}{lll}
\hline Final end results & No. & $\%$ \\
\hline Non satisfactory & 9 & 22.5 \\
Satisfactory & 31 & 77.5 \\
\hline
\end{tabular}

\section{1- Visual Analogue Scale of pain (VAS):}

Performing Friedman test and Post Hoc Test (Dunn's), the mean VAS scale in the pre-injection period was 8.03 while at the end of follow-up period the mean VAS score changed to 2.28 and there were significant differences between readings of pre-injection and final post-injection VAS Scale as $p$-value $<0.001$ as shown in (Table 2).

\section{2- Roles and Maudsley score}

Nine patients $(22.5 \%)$ had excellent results, twenty two patients $(55 \%)$ had good results, seven patients $(17.5 \%)$ had accepted results and two patients $(5 \%)$ had poor results. Performing Chi square or Monte Carlo test, there were significant differences between readings of pre-injection and final post-injection Roles and Maudsley score as $p$-value $<0.001$ as shown in (Table 3 ).

\section{3- American Orthopedic Foot and Ankle Society (AOFAS):}

Performing F-test (ANOVA), the mean AOFAS score in the pre-injection period was 49.8 while at the end of follow-up period the mean AOFAS score 
changed to 82 and there were significant differences between readings of pre-injection and final post- injection AOFAS score as $p$-value $<0.001$ as shown in (Table 4).

Table (2): Descriptive analysis of the studied cases according to Visual Analogue Scale of pain (VAS).

\begin{tabular}{llllllll}
\hline VAS & Preinjection & 1 month & 2 months & 3 months & 6 months & Frc $^{2}$ & $p$ \\
\hline Min.-Max. & $6.0-10.0$ & $3.0-7.0$ & $2.0-5.0$ & $1.0-5.0$ & $1.0-5.0$ & $153.267 *$ & $<0.001 *$ \\
Mean \pm SD. & $8.03 \pm 1.12$ & $4.55 \pm 1.11$ & $3.08 \pm 0.92$ & $1.75 \pm 1.03$ & $2.28 \pm 1.18$ & & \\
Median & 8.0 & 4.0 & 3.0 & 1.03 & 2.0 & & \\
$p_{1}$ & & $0.005 *$ & $<0.001 *$ & $<0.001 *$ & $<0.001 *$ & & \\
\hline
\end{tabular}

$\chi^{2}$ : Chi square for Friedman test, Sig. between periods was done using Post Hoc Test (Dunn's).

$p: p$-value for comparison between different periods.

$p_{*} 1: p$-value for comparison between pre-operative and each other period. : Statistically significant at $p \leq 0.05$.

Table (3): Distribution of the studied cases according to roles and Maudsley score.

\begin{tabular}{|c|c|c|c|c|c|c|c|c|c|c|}
\hline \multirow{2}{*}{$\begin{array}{l}\text { R \& M } \\
\text { score }\end{array}$} & \multicolumn{2}{|c|}{ Preinjection } & \multicolumn{2}{|c|}{1 month } & \multicolumn{2}{|c|}{2 months } & \multicolumn{2}{|c|}{3 months } & \multicolumn{2}{|c|}{6 months } \\
\hline & No. & $\%$ & No. & $\%$ & No. & $\%$ & No. & $\%$ & No. & $\%$ \\
\hline Poor & 14 & 35.0 & 0 & 0.0 & 0 & 0.0 & 0 & 0.0 & 2 & 5.0 \\
\hline Accepted & 26 & 65.0 & 22 & 55.0 & 11 & 27.5 & 2 & 5.0 & 7 & 17.5 \\
\hline Good & 0 & 0.0 & 18 & 45.0 & 21 & 52.5 & 17 & 42.5 & 22 & 55.0 \\
\hline Excellent & 0 & 0.0 & & 0.0 & & 20.0 & & 52.5 & 9 & 22.5 \\
\hline$p_{1}$ & & & \multicolumn{2}{|c|}{$<0.001 *$} & \multicolumn{2}{|c|}{$<0.001 *$} & \multicolumn{2}{|c|}{$<0.001 *$} & \multicolumn{2}{|c|}{$<0.001 *$} \\
\hline
\end{tabular}

$p$ 1: $p$-value for Chi square or Monte Carlo test for comparison between pre-operative and each other period.

$*$ : Statistically significant at $p \leq 0.05$.

Table (4): Distribution of the studied cases according to American Orthopedic Foot and Ankle Society (AOFAS) score.

\begin{tabular}{lllllllc}
\hline AOFAS & Preinjection & 1 month & \multicolumn{1}{c}{2 months } & 3 months & 6 months & \multicolumn{1}{c}{ F } & $p$ \\
\hline Min.-Max. & $35.0-62.0$ & $59.0-85.0$ & $66.0-87.0$ & $66.0-90.0$ & $59.0-90.0$ & $262.946^{*}$ & $<0.001 *$ \\
Mean \pm SD. & $49.80 \pm 8.93$ & $69.20 \pm 8.31$ & $79.10 \pm 6.87$ & $84.47 \pm 8.06$ & $82.0 \pm 8.94$ & & \\
Median & 51.0 & 69.0 & 82.0 & 90.0 & 85.0 & & \\
$p_{1}$ & & $<0.001 *$ & $<0.001 *$ & $<0.001 *$ & $<0.001 *$ & & \\
\hline
\end{tabular}

F : F-test (ANOVA) with repeated measures.

$p: p$-value for F-test (ANOVA) with repeated measures for comparing between different periods.

$p_{*} 1: p$-value for comparison between pre-operative and each other period. : Statistically significant at $p \leq 0.05$.

Relation between final end results and duration of symptoms:

Studying the relation between duration of symptoms and the results showed to be statistically significant as shown in (Table 5).

Relation between final end results and previous corticosteroid injection:

Studying the relation between previous corticosteroid injection (once) and the results showed to be statistically significant as shown in (Table 6).

As regard the relation between previous corticosteroid injection (once) and the results showed to be statistically significant in our study with $p=$ 0.038 as patients with previous corticosteroid injection had less satisfactory results than patients without previous corticosteroid injection.

This finding may be due to resistance of the patients to injection therapy from the start or failed corticosteroid injection in the plantar fascia or failed PRP injection as a result of plantar fascia rupture, atrophy of heel pad fat and fat necrosis caused by previous corticosteroid injection, for further studies.

Relation between final end results and previous corticosteroid injection:

Studying the relation between presence of subcalaneal heel spur and the results showed to be statistically insignificant as shown in (Table 7). 
Table (5): Relation between final end results and duration of symptoms.

\begin{tabular}{|c|c|c|c|c|c|c|}
\hline \multirow{3}{*}{$\begin{array}{l}\text { Duration of } \\
\text { symptoms }\end{array}$} & \multicolumn{4}{|c|}{ Final and results } & \multirow{2}{*}{\multicolumn{2}{|c|}{$\begin{array}{c}\text { Total } \\
(\mathrm{n}=40)\end{array}$}} \\
\hline & \multicolumn{2}{|c|}{$\begin{array}{c}\text { Non } \\
\text { satisfactory } \\
(\mathrm{n}=19) \\
\end{array}$} & \multicolumn{2}{|c|}{$\begin{array}{l}\text { Satisfactory } \\
\quad(\mathrm{n}=31)\end{array}$} & & \\
\hline & No. & $\% \mathrm{I}$ & No. & $\% \mathrm{I}$ & No. & $\%$ \\
\hline $\begin{array}{l}\text { Less than } 6 \text { months } \\
6-12 \text { months } \\
\text { More than } 12 \text { months } \\
\chi^{2} \\
\mathrm{MC}_{p}\end{array}$ & $\begin{array}{l}1 \\
3 \\
5\end{array}$ & $\begin{array}{l}11.1 \\
33.3 \\
55.6\end{array}$ & $\begin{array}{l}17 \\
10 \\
4 \\
7.9 \\
0.0\end{array}$ & $\begin{array}{l}54.8 \\
32.3 \\
12.9 \\
* \\
*\end{array}$ & $\begin{array}{l}18 \\
13 \\
9\end{array}$ & $\begin{array}{l}45.0 \\
32.5 \\
22.5\end{array}$ \\
\hline $\begin{array}{ll}\chi^{2} & : \text { Chi square test. } \\
\text { MC } & : \text { Monte Carlo. } \\
p & : p \text {-value for associa } \\
& \text { of symptoms. } \\
* & : \text { Statistically signific }\end{array}$ & be & $\begin{array}{l}\text { en } \mathrm{f} \\
.05\end{array}$ & & cults & & tion \\
\hline
\end{tabular}

Table (6): Relation between final end results and previous corticosteroid injection.

\begin{tabular}{|c|c|c|c|c|c|c|}
\hline \multirow{3}{*}{$\begin{array}{l}\text { Previous } \\
\text { corticosteroid } \\
\text { injection } \\
\text { (once) }\end{array}$} & \multicolumn{4}{|c|}{ Final and results } & \multirow{2}{*}{\multicolumn{2}{|c|}{$\begin{array}{c}\text { Total } \\
(n=40)\end{array}$}} \\
\hline & \multicolumn{2}{|c|}{$\begin{array}{l}\text { Non satisfactory } \\
\qquad(\mathrm{n}=9)\end{array}$} & \multicolumn{2}{|c|}{$\begin{array}{l}\text { Satisfactory } \\
\qquad(n=31)\end{array}$} & & \\
\hline & No. & $\%$ & No. & $\%$ & No. & $\%$ \\
\hline No & 3 & 33.3 & 24 & 77.4 & 27 & 67.5 \\
\hline Yes & 6 & 66.7 & 7 & 22.6 & 13 & 32.5 \\
\hline$x^{2}$ & & & 3.18 & & & \\
\hline $\mathrm{FE}_{p}$ & & & 0.03 & & & \\
\hline \multicolumn{7}{|c|}{$\begin{array}{l}\chi^{2}: \text { Chi square test. } \\
\text { FE : Fisher Exact. }\end{array}$} \\
\hline \multicolumn{7}{|c|}{$\begin{array}{l}p \quad: p \text {-value for association between final end results and previous } \\
\text { CS injection. } \\
\text { : Statistically significant at } p \leq 0.05 \text {. }\end{array}$} \\
\hline
\end{tabular}

Table (7): Relation between final end results and X-ray finding (presence of subcalaneal heel spur).

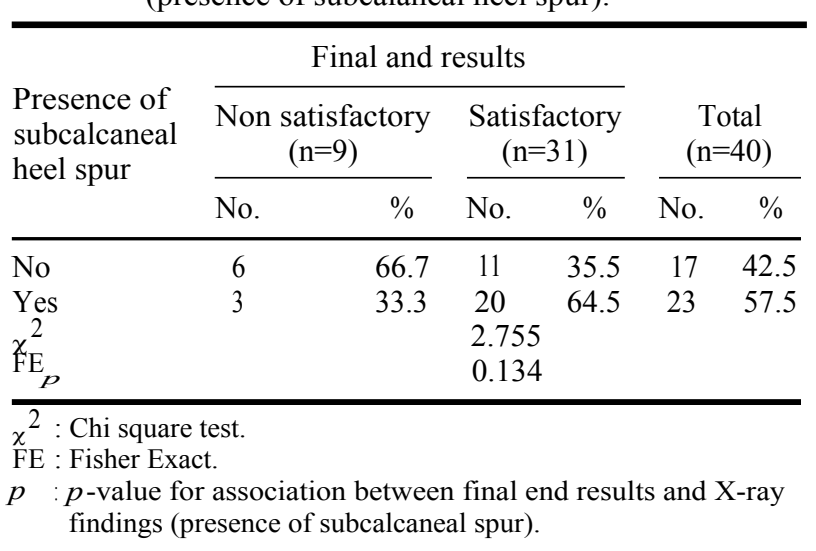

\section{Relation between final end results and serum} uric acid level:

Studying the relation between serum uric acid level and the results showed to be statistically insignificant as shown in (Table 8).
Studying the relation between serum uric acid level in blood and the results, there was no statistical significance with $p=0.602$ so serum uric acid level does not play a role in diagnosis of plantar fasciitis.

Serum uric acid level is tested to rule out gouty arthritis as uric acid is usually raised in gouty arthritis not plantar fasciitis, for further studies.

Table (8): Relation between final end results and serum uric acid level.

\begin{tabular}{|c|c|c|c|c|c|c|}
\hline \multirow{3}{*}{$\begin{array}{l}\text { Serum } \\
\text { uric } \\
\text { acid } \\
\text { level }\end{array}$} & \multicolumn{4}{|c|}{ Final and results } & \multirow{2}{*}{\multicolumn{2}{|c|}{$\begin{array}{l}\text { Total } \\
(n=40)\end{array}$}} \\
\hline & \multicolumn{2}{|c|}{$\begin{array}{l}\text { Non satisfactory } \\
\qquad(n=9)\end{array}$} & \multicolumn{2}{|c|}{$\begin{array}{l}\text { Satisfactory } \\
\qquad(n=31)\end{array}$} & & \\
\hline & No. & $\%$ & No. & $\%$ & No. & $\%$ \\
\hline $\begin{array}{l}\text { Normal } \\
\text { High } \\
\chi^{2} \\
\mathrm{FE}_{p}\end{array}$ & \multicolumn{6}{|c|}{$\begin{array}{l}0.475 \\
0.602\end{array}$} \\
\hline $\begin{array}{r}\chi^{2}: \text { Chi } \\
\text { FE }: \text { Fish } \\
p \quad: p \text {-va } \\
\text { acid }\end{array}$ & $\begin{array}{l}\text { are te } \\
\text { xact. } \\
\text { for as } \\
\text { l. }\end{array}$ & betwe & na & resul & & uric \\
\hline
\end{tabular}

\section{Discussion}

In the present study, Satisfactory results were obtained in 31 patients (77.5\%). 9 patients $(22.5 \%)$ of them had excellent results and 22 patients $(55 \%)$ had good results. The unsatisfactory results were found in 9 patients $(22.5 \%) .7$ patients $(17.5 \%)$ of them had accepted results and 2 patients $(5 \%)$ had poor results.

This final results agree with Barrett et al., [12] who found that seven of nine patients had complete resolution of their plantar fascial pain for a 77.8 percent success rate after one year.

Furthermore, the results nearly agree with $\mathrm{Ku}$ mar et al., [13] who stated that only 28 patients $(64 \%)$ of 44 patients were satisfied (31 patients $(77.5 \%)$ were satisfied in the presenting study) and this may be due to exclusion of diabetic patients in the presenting study compared to Kumar et al., [13] study.

Also, the results nearly agree with Ragab and Othman [14] study in which 22 patients $(88 \%)$ were completely satisfied, 2 patients $(8 \%)$ were satisfied with reservations, and 1 patient (4\%) was unsatisfied with the end result of PRP injection and this may be due to different method of PRP preparation between the presenting study and Ragab and Othman [14] study. (3000rpm for 7 minutes then 4000 rpm for 5 minutes in the current study but 3,000 rpm for $15 \mathrm{~min}$ in Ragab and Othman [14] study). 
Furthermore, the end results nearly agree with Othman and Hegazy [15] who stated that 20 cases of 27 patients $(74.07 \%)$ were satisfied, 4 patients (14.81\%) were satisfied with reservation, and 3 patients $(11.11 \%)$ were not satisfied and this also may be different method of preparation. $(25 \mathrm{ml}$ blood were obtained and centrifuged for 7 minutes with 3000rpm then 5 minutes with 4000rpm for in this study compared to $50 \mathrm{ml}$ withdrawal and centrifugion for 15min with 3000rpm in Othman and Hegazy [15] study).

In the present study, the mean VAS scale in the pre-injection period was 8.03 while at the end of follow-up period the mean VAS score was 2.28 and there were significant differences between readings of pre-injection and final post-injection in VAS Scale as $p$-value $<0.001$ which agrees with Martinelli et al., [2] . Study in that average VAS scores decreased from 7.1 to 2.1 after 12 months of followed-up and O'Malley et al., [16] study in which the mean VAS score improved from 7 to 4 .

Also, the results agree with Ragab and Othman [14] study who illustrated that the VAS score improved from 9.1 pre-treatment to 1.6 post-treatment with average followed-up of 10.3 months, JiménezPérez et al., [17] study in that the mean VAS scale in the pre-injection period was 8.25 while at the end of follow-up period the mean VAS score changed to 1.85 and Kumar et al., [13] who illustrated that the VAS score improved from 7.7 to 4.2 .

Furthermore, the presenting results agree with Ahmed A. Baz et al., [18] study in which VAS score showed improvement from 8.14 pre-injection to 2.59 at the $4^{\text {th }}$ month post-injection and Akiahin et al., [5] study in that the mean VAS heel pain scores significantly lowered from 7.33 to 3.93 after 6 months in the PRP group.

In the current study, there was a significant difference between the mean AOFAS score in the pre-injection period and at the end of follow-up period $(p<0.001)$ and the mean AOFAS score in the pre-injection period was 49.8 while at the end of follow-up period the mean AOFAS score changed to 82 that agrees with Kumar et al., [13] who stated that the mean AOFAS score in the preinjection period was 60.6 while at the end of followup period the mean AOFAS score changed to 81.9.

Also, the results agree with Gogna et al., [19] study in which the AOFAS at presentation was 51.5 , that improved to 89.1 at 6 months followup, Jiménez-Pérez et al., [17] study in which there was significant difference as regard to AOFAS from 47.05 to 92.10 and Lopez-Gavito et al., [20] who illustrated that the AOFAS improved from 39 to 97 by week 16 after PRP treatment.

In the current study, the relation between modified Roles and Maudsley score and the results showed to be statistically significant with $(p<0.001)$ and there was significant improvement from $35 \%$ of patients who were poor and $65 \%$ were acceptable pre-injection to $22.5 \%$ of patients who became excellent, 55\% good, $17.5 \%$ acceptable and 5\% poor after 6 months post-injection that nearly agree with Baz et al., [18] who showed significant improvement from $18.2 \%$ of patients who were poor and $81.8 \%$ were acceptable pre-injection to $59.1 \%$ of patients who became excellent, $31.8 \%$ good, $4.5 \%$ acceptable and $4.5 \%$ poor.

Also, according to the modified criteria of the Roles and Maudsley score, the final end results in the present study were 9 patients with excellent results $(22.5 \%), 22$ patients with good results (55\%), 7 patients with accepted results $(17.5 \%)$ and 2 patients with poor results $(5 \%)$ that nearly agree with Martinelli et al., [2] who reported excellent final results in 9 patients $(64.3 \%)$, good in 2 patients $(14.3 \%)$, acceptable in 2 patients $(14.3 \%)$ and poor in 1 patient $(7.1 \%)$.

In the present study, the duration of symptoms before injection ranged from 4 to 18 months with a mean duration of 11 months that agrees with O'Malley et al., [16] who stated that the duration of symptoms before injection ranged from 6 to 12 months with average duration of 9 months.

Furthermore, the duration of symptoms in the study agrees with Ragab and Othman [14] who illustrated that the duration of symptoms before injection ranged from 8 to 10 months with average duration of 9.1 months.

Also, the duration of symptoms agrees with Martinelli et al., [2] study in that the mean symptoms duration from the beginning of symptoms to enrolment in the study was $9.9 \pm 2.6$ months.

There was a significant difference between duration of symptoms and the results with $p=0.014$ as patients with longer duration of symptoms before injection had more unsatisfactory results than shorter ones and this may be due to repeated microtrauma and degeneration of plantar fascia with long duration of symptoms before injection, for further studies.

As regard to the relation between presence of subcalaneal heel spur in X-Ray and the results, there was no statistical significance with $p=0.134$ 
which agrees with Jiménez-Pérez et al., [17] who illustrated that the presence of calcaneal spurs were not connected with plantar fasciitis and were considered incidental findings. Also, U gurlar et al., [21] elucidated that the plain radiographs may show the heel spurs but US findings support the diagnosis when the plantar fascia is thickened ( $>4$ to $4.5 \mathrm{~mm}$ ) and hypoechoic.

\section{Conclusions:}

- Platelet rich plasma injection at the site of the heel pain resulted in relief of symptoms in most of patients $(77.5 \%)$ with chronic plantar fasciitis especially those who were refractory to other conservative measures.

- Platelet rich plasma provides a minimally invasive treatment for chronic plantar fasciitis avoiding the side effect of surgery and other conservative modalities.

- Most patients show improvement during one month, two months and three months after injection, but after three months to the end of followup at six months, there is little rebound of symptoms that may increase the need for a second local injection of platelet rich plasma later on but this needs further studies.

- The age, gender, side, occupation, presence of subcalcaneal heel spur in X-ray and serum uric acid level of patients had no influence on the final results.

- Duration of symptoms before injection had influence on the final end results, as those with longer duration of symptoms showed little improvement after injection.

- Failure of previous local corticosteroid injection may increase the possibility of unsatisfactory results in patients who will prepared to have a local injection of platelet rich plasma so it is not recommended to use local injection of platelet rich plasma in those who had previous local corticosteroid injection but this needs further studies.

- The side effects of platelet rich plasma therapy are minimal. There may be increased pain at the site of injection, but the incidence of other complications such as infection, nerve injuries, tissue damage were not recorded in our study.

\section{References}

1- OMAR A.S., IBRAHIM M.E., AHMED A.S. and SAID M.: Local injection of autologous platelet rich plasma and corticosteroid in treatment of lateral epicondylitis and plantar fasciitis: Randomized clinical trial. The Egyptian Rheumatologist, 34 (2): 43-9, 2012.
2- MARTINELLI N., MARINOZZI A., CARNÌ S., TROVATO U., BIANCHI A. and DENARO V.: Platelet-rich plasma injections for chronic plantar fasciitis. International Orthopaedics, 37 (5): 839-42, 2012.

3- CLELAND J.A., ABBOTT J.H., KIDD M.O., STOCKWELL S., CHENEY S., GERRARD D.F., et al.: Manual Physical Therapy and Exercise Versus Electrophysical Agents and Exercise in the Management of Plantar Heel Pain: A Multicenter Randomized Clinical Trial. Journal of Orthopaedic \& Sports Physical Therapy, 39 (8): 573 $85,2009$.

4- ROBERTS J.R., CUSTALOW C.B. and THOMSEN T.W.: Roberts and Hedges' clinical procedures in emergency medicine and acute care: Elsevier; 2019.

GRUYOL D., YÜKSEL H.Y., HAPA

O., DOGAN Ö., ÇELEBI L., et al.: The comparison of the effect of corticosteroids and platelet-rich plasma (PRP) for the treatment of plantar fasciitis. Archives of Orthopaedic and Trauma Surgery, 132 (6): 781-5, 2012.

6- BEESON P.: Plantar fasciopathy: Revisiting the risk factors. Foot and Ankle Surgery, 20 (3): 160-5, 2014.

7- CRAWFORD F., ATKINS D. and EDWARDS J.: Interventions for treating plantar heel pain. The Foot, 11 (4): 228-50, 2001.

8- ROSENBAUM A.J., DiPRETA J.A. and MISENER D.: Plantar Heel Pain. Medical Clinics of North America, 98 (2): 339-52, 2014.

9- SAMPSON S., GERHARDT M. and MANDELBAUM B.: Platelet rich plasma injection grafts for musculoskeletal injuries: A review. Current Reviews in Musculoskeletal Medicine, 1 (3-4): 165-74, 2008.

10-MAZZOCCAA.D., McCARTHY M.B.R., CHOWANIEC D.M., DUGDALE E.M., HANSEN D., COTE M.P., et al.: The Positive Effects of Different Platelet-Rich Plasma Methods on Human Muscle, Bone, and Tendon Cells. The American Journal of Sports Medicine, 40 (8): 1742 _9, 2012.

11- FOSTER T.E., PUSKAS B.L., MANDELBAUM B.R., GERHARDT M.B. and RODEO S.A.: Platelet-Rich Plasma. The American Journal of Sports Medicine, 37 (11): 2259-72, 2009.

12- BARRETT B.S.L. and ERREDGE S.E.: Feature: Growth factors for chronic plantar fasciitis. Podiatry Today-ISSN, 17: 1045-7860, 2004.

13- KUMAR V., MILLAR T., MURPHY P.N. and CLOUGH T.: The treatment of intractable plantar fasciitis with platelet-rich plasma injection. The Foot, 23 (2-3): 74-7, 2013.

14- RAGAB E.M.S. and OTHMAN A.M.A.: Platelets rich plasma for treatment of chronic plantar fasciitis. Archives of Orthopaedic and Trauma Surgery, 132 (8): 1065-70, 2012.

15- OTHMAN A.M.A. and HEGAZY I.H.A.: Endoscopic plantar fasciotomy versus injection of platelet-rich plasma for resistant plantar fasciopathy. Journal of Orthopaedics, 12: S176-S81, 2015.

16- O'MALLEY M.J., VOSSELLER J.T. and GU Y.: Successful Use of Platelet-Rich Plasma for Chronic Plantar Fasciitis. HSS Journal®, 9 (2): 129-33, 2013. 
17- JIMÉNEZ-PÉREZ A.E., GONZALEZ-ARABIO D., DIAZ A.S., MADERUELO J.A. and RAMOS-PASCUA L.R.: Clinical and imaging effects of corticosteroids and plateletrich plasma for the treatment of chronic plantar fasciitis: A comparative non randomized prospective study. Foot and Ankle Surgery, 2018.

18- BAZ A.A., GAD A.M. and WALY M.R.: Ultrasound guided injection of platelet rich plasma in cases of chronic plantar fasciitis. The Egyptian Journal of Radiology and Nuclear Medicine, 48 (1): 125-32, 2017.

19- GOGNA P., GABA S., MUKHOPADHYAY R., GUPTA R., ROHILLA R. and YADAV L.: Plantar fasciitis: A randomized comparative study of platelet rich plasma and low dose radiation in sportspersons. The Foot, 28: 16-9, 2016.

20- LOPEZ-GAVITO E., GOMEZ-CARLIN L., PARRATELLEZ P. and VAZQUEZ-ESCAMILLA J.: Plateletrich plasma for managing calcaneus tendon tendinopathy and plantar fasciitis. Acta Ortopedica Mexicana, 25 (6): 380-5, 2011.

21- UGURLAR M., SÖNMEZ M.M., U GURLAR Ö.Y., AD1YEKE L., Y1LD1R1M H. and EREN O.T.: Effectiveness of Four Different Treatment Modalities in the Treatment of Chronic Plantar Fasciitis During a 36-Month Follow-Up Period: A Randomized Controlled Trial. The Journal of Foot and Ankle Surgery, 57 (5): 913-8, 2018.

\section{إستخدام البلازما الغنية بالصفائح الدموية

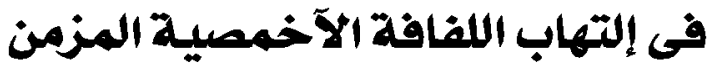

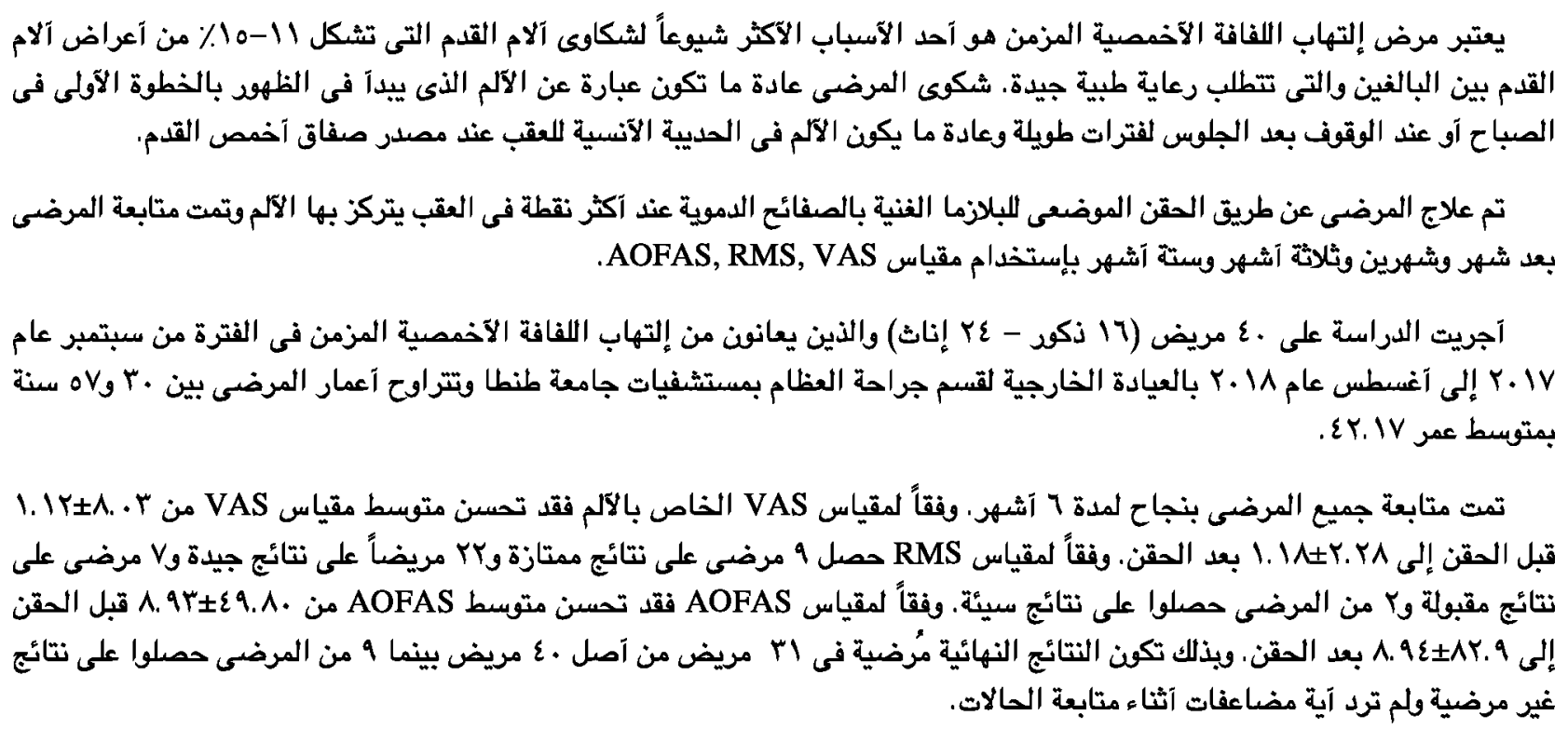

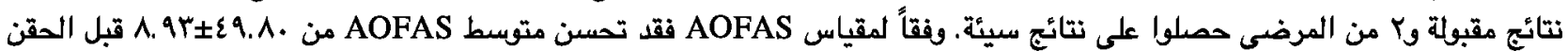

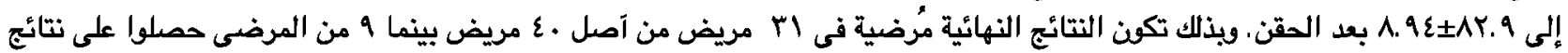
غير مرضية ولم ترد آية مضاعفات آثناء مثابعة الحالات. 